\title{
The use of core needle biopsy as first-line in diagnosis of thyroid nodules reduces false negative and inconclusive data reported by fine-needle aspiration
}

\author{
Pierpaolo Trimboli ${ }^{1 \dagger}$, Naim Nasrollah ${ }^{2 \dagger}$, Leo Guidobaldi ${ }^{3}$, Silvia Taccogna ${ }^{3}$, Davide Domenico Cicciarella Modica ${ }^{3}$, \\ Stefano Amendola', Francesco Romanelli ${ }^{4}$, Andrea Lenzi ${ }^{4}$, Giuseppe Nigri ${ }^{{ }^{*}}$, Marco Centanni ${ }^{4,6}$, Luca Giovanella ${ }^{7}$, \\ Stefano Valabrega ${ }^{5}$ and Anna Crescenzi ${ }^{3}$
}

\begin{abstract}
Background: The reported reliability of core needle biopsy (CNB) is high in assessing thyroid nodules after inconclusive fine-needle aspiration (FNA) attempts. However, first-line use of CNB for nodules considered at risk by ultrasonography (US) has yet to be studied. The aim of this study were: 1) to evaluate the potential merit of using CNB first-line instead of conventional FNA in thyroid nodules with suspicious ultrasonographic features; 2) to compare CNB and FNA as a first-line diagnostic procedure in thyroid lesions at higher risk of cancer.

Methods: Seventy-seven patients with a suspicious-appearing, recently discovered solid thyroid nodule were initially enrolled as study participants. No patients had undergone prior thyroid fine-needle aspiration/biopsy. Based on study design, all patients were proposed to undergo CNB as first-line diagnostic aspiration, while those patients refusing to do so underwent conventional FNA.

Results: Five patients refused the study, and a total of 31 and 41 thyroid nodules were subjected to CNB and FNA, respectively. At follow-up, the overall rate of malignancy was of $80 \%$ (CNB, 77\%; FNA, 83\%). However, the diagnostic accuracy of CNB (97\%) was significantly $(P<0.05)$ higher than that of FNA $(78 \%)$. In one benign lesion, CNB was inconclusive. Four (12\%) of the 34 cancers of the FNA group were not initially diagnosed because of false negative $(N=1)$, indeterminate $(N=2)$ or not adequate $(N=1)$ samples.
\end{abstract}

Conclusions: CNB can reduce the false negative and inconclusive results of conventional FNA and should be considered a first-line method in assessing solid thyroid nodules at high risk of malignancy.

Keywords: Thyroid cancer, Core needle biopsy (CNB), Ultrasonography, Fine-needle aspiration (FNA)

\section{Background}

Ultrasound (US) examination is the standard method for stratifying risk for malignancy in both palpable and nonpalpable thyroid lesions, thus determining the need for fine-needle aspiration (FNA) [1,2]. A number of publications attest to the specific features by US and color flow Doppler (CFD) that are suggestive of malignancy,

\footnotetext{
* Correspondence: giuseppe.nigri@uniroma1.it

${ }^{\dagger}$ Equal contributors

${ }^{5}$ Department of Surgical and Medical Sciences, Sapienza University, Ospedale S. Andrea, Rome, Italy

Full list of author information is available at the end of the article
}

namely hypoechogenicity, irregular or blurred margins, microcalcifications, taller shape, and vascular signals $[3,4]$. In addition to conventional US, elastography is believed to improve the management of thyroid lesions, increasing the sensitivity of US-CFD when done in tandem [5]. As a consequence, cold nodules with the above features qualify for biopsy $[1,2]$.

Although FNA can accurately distinguish thyroid cancers from benign lesions, there are a number of limitations [1,2]. The chief drawback is that up to 25 to $30 \%$ of cytologic samplings are inconclusive (that is, indeterminate or inadequate), often necessitating diagnostic 
surgery $[1,2]$. A low percentage of these ultimately prove malignant by histology, thus a means to further differentiate benign and cancerous lesions is advantageous. Moreover, many sources indicate that the falsenegative rate of FNA cytology with respect to thyroid cancers is not insignificant [6-8]. However, thyroid core needle biopsy (CNB) has recently been cited as a reliable test [9-14]. The microhistology of CNB samplings enables diagnosis in a large percentage of thyroid lesions deemed indeterminate or inadequate by FNA. The semiautomated CNB needles used are of small caliber (20 to 22 gauge), allowing full access to both large and small thyroid nodules with few complications and high patient tolerability [15]. Although the popularity of CNB has risen worldwide, this technique has primarily assumed a lesser role in thyroid lesions diagnosis, reserved for instances of inconclusive cytology. There are no data on its use as a first-line diagnostic tool in thyroid nodules at high risk of malignancy.

This study was designed to evaluate the potential merit of using CNB first-line instead of conventional FNA to assess thyroid nodules with suspicious US features. Thyroid nodule diagnostic results with CNB were compared with outcomes of patients subjected to FNA.

\section{Methods}

\section{Patients}

From September 2012 to April 2013, all patients referring to Ospedale Israelitico of Rome with a recently discovered suspicious thyroid nodule were selected for this study. None of the patients had undergone prior thyroid nodule aspiration/biopsy. All nodules were found to be solid at US and hot lesions were excluded. Seventyseven patients (females, 64; males, 13) granting informed consent were initially enrolled as study participants. The study design proposed that all patients undergo CNB as first-line diagnostic aspiration, and those patients refusing $\mathrm{CNB}$ were tested by conventional FNA.

\section{Ultrasound examination}

As in an earlier prospective multicenter study of ours [5], US risk stratification was aligned with Society of Radiologists in Ultrasound [16] and AACE/AME/ETA criteria [1]. The pattern of vascular signals within nodules was scrutinized by CFD and designated as absent, perinodular, or intranodular [17]. Real-time elastography (RTE) was also performed, ranking nodules as class I (prevalence of red and green color), class II (green with prevalence in more than $50 \%$ of the nodule), class III (blue in at least $50 \%$ of nodule), or class IV (blue with prevalence in at least $75 \%$ of nodule) [5]. To qualify as an 'at-risk' nodule by US examination, at least two of the following features were required: marked hypoechogenicity, microcalcifications, irregular margins, taller rather than wider shape, intranodular vascularization, and RTE class III to IV.

In all patients, US, CFD, and RTE examinations were performed prior to aspiration by an experienced endocrinologist, using an EsaoteMyLab system (Esaote, Genova, Italy) with linear probe. Ultrasonographic evaluation of each nodule was repeated by a second expert examiner. Any discordant cases were mutually resolved by the two physicians for definitive classification. Before the study began, US technique was standardized by the two operators for procedural reproducibility [5].

\section{FNA and CNB procedures}

Patients were instructed to refrain from anticoagulants during the five days prior to FNA and CNB. Both biopsies were performed at Ospedale Israelitico of Rome by the same experienced surgeon in freehand fashion under US guidance. For FNA, a 23-gauge needle was utilized, while for CNB a 21-gauge Menghini cutting needle (Biomol, Hospital Service, Rome, Italy) was employed, as previously described $[14,15]$. Two needle passes were made for both biopsies. Before CNB, a local anesthetic was administered.

\section{Cytologic and microhistologic examination}

Cytologic specimens were screened by an expert cytopathologist, conforming to AACE/AME/ETA [1] as follows: class 1 (inadequate), class 2 (benign), class 3 (indeterminate), class 4 (suspicious of malignancy), or class 5 (malignant).

Formalin-fixed needle cores underwent automated processing for embedding in paraffin, as we previously detailed $[14,15]$. Serial sections at $4 \mu \mathrm{m}$ were affixed to polarized slides. A single H\&E-stained slide was generated, and the remainder were immunostained for galectin-3, cytokeratin19 and HBME-1 (Thermo Fisher Scientific, Fremont, CA, USA), using a biotin-free peroxidase method. All specimens were evaluated by an experienced pathologist.

All cytologic and microhistologic samples were also reviewed by a second pathologist. In case of disagreement, definitive reporting was achieved by mutual consensus.

\section{Follow-up}

Final histologic examination was the 'gold standard' in all patients. Thyroid tumor classification relied on the most recent World Health Organization histologic criteria [18].

\section{Statistical analysis}

Comparison of frequency was made by chi-squared test or Fisher exact test, as appropriate. Means and standard deviations were compared by the Student's t-test. Statistical analysis was performed using Graph Pad Prism (Graph Pad Software Inc, La Jolla, CA, USA). 


\section{Results}

Five patients declined to participate in the study, and the final series included 72 nodules (size $11.5 \pm 4.8 \mathrm{~mm}$ ) from 72 patients (females, 60; males, 12; mean age, $50.4 \pm$ 13.7 years). A proportion of these patients consented to undergo $\mathrm{CNB}(\mathrm{N}=31)$, while the remainder refused $\mathrm{CNB}$ and were tested via routine FNA $(\mathrm{N}=41)$. Table 1 details the US nodules characteristics of the two groups.

\section{CNB group}

Mean size of the 31 nodules subjected to CNB was $12.3 \pm$ $3.8 \mathrm{~mm}$. Of these, 30 (96.8\%) were diagnostic: 24 cancers and 6 benign lesions. One nodule (3.2\%) was found to be inadequate. The histologic examination confirmed cancer in all 24 cases (classic papillary cancers, 14; follicular variant of papillary cancer, 9; medullary carcinoma, 1) and benign lesions in the remaining 6 specimens (nodular thyroiditis, 4; microfollicular hyperplasia, 2). The inadequate CNB sampling proved to be microfollicular hyperplasia (Figure 1).

\section{FNA group}

Of the 41 nodules (mean size $11.2 \pm 5.1 \mathrm{~mm}$ ) subjected to FNA, 33 (80.5\%) were initially diagnostic (class 5, 17; class 4, 13; class 2,3$)$. The other $8(19.5 \%)$ were mostly indeterminate, with the exception of one inadequate specimen (Figure 1). Histologic confirmation of cancer was obtained for all patients with class 4 or 5 cytology. FNA was repeated in patients with class 2: 2 nodules were benign (class 2) with microfollicular hyperplasia at histology, while the other one was cancer (class 5) with postsurgical follicular variant of papillary carcinoma (Figure 2). The eight nodules with inconclusive (class 1 or class 3) results by FNA were selected for complementary CNB sampling. Of these, five were benign lesions (nodular thyroiditis, four; microfollicular hyperplasia, one) and three were considered malignant, as confirmed

Table 1 Main ultrasound characteristics of 72 solid nodules included in the study

\begin{tabular}{lccc}
\hline & CNB group & FNA group & $\boldsymbol{P}$ \\
\hline Size $(\mathrm{mm})$ & $12.3 \pm 3.8$ & $11.2 \pm 5.1$ & 0.31 \\
Marked hypoechogenicity & $26(82.9 \%)$ & $37(90.2 \%)$ & 0.48 \\
Taller shape & $5(16.1 \%)$ & $7(17.1 \%)$ & 0.83 \\
Microcalcifications & $14(45.2 \%)$ & $21(51.2 \%)$ & 0.78 \\
Intranodular vascularization & $17(54.8 \%)$ & $20(48.8 \%)$ & 0.78 \\
Score III to IV at elastography & $26(83.9 \%)$ & $32(78.0 \%)$ & 0.75 \\
More than two risk features & $15(48.4 \%)$ & $17(41.5 \%)$ & 0.72 \\
\hline
\end{tabular}

Legend: CNB, core needle biopsy; FNA, fine-needle aspiration. Marked hypoechogenicity, solid hypoechoic nodule with no cystic areas. Taller shape, taller than wide shaped nodule. Microcalcifications, hyperechoic punctuations $<2 \mathrm{~mm}$. Intranodular vascularization, intralesional vascular signal. Score III to IV at elastography, blue color in more than $50 \%$ of the nodule. after surgery. Histologic features of 34 cancers from the FNA group are shown in Table 2.

\section{Comparison of the results from the two groups}

No significant difference was found in nodule size and US characteristics between the two groups (Table 1). At followup, the overall rate of malignancy in the 72 patients was 80.5\% (CNB, 77.4\%; FNA, 82.9\%). Diagnostic accuracy was significantly $(P<0.05)$ higher in CNB $(30 / 31 ; 96.8 \%)$ than in FNA $(32 / 41,78 \%)$ group. No false negatives were recorded in CNB samples. In the FNA series, 4 (12\%) of the 34 cancers were not initially diagnosed (false negative, 1 ; indeterminate, 2; not adequate, 1 ) and a $2.5 \%$ rate of false negative (class 2) results was recorded (Figure 1). Similar to our previous experiences $[15,16]$, no complications were recorded after the biopsies.

\section{Discussion}

Ultrasonographic risk stratification is the standard means of determining the need for biopsy in patients with thyroid nodules. Although FNA is the most costeffective method of thyroid biopsy at present [1], a considerable percentage of cytologic preparations are diagnostically inconclusive. Molecular or genetic markers and clinical or instrumental features can be used to bolster FNA outcomes [19-24] but diagnostic surgery is often unavoidable $[1,2,24]$. CNB was introduced to better assess these thyroid nodules, and this approach is gaining momentum [9-14]. Unfortunately, its role has been limited to a complementary use in patients with inconclusive FNA results. Data from previous studies indicate that up to $98 \%$ of nodules indeterminate by FNA are diagnosable by $\mathrm{CNB}$, and the combination of $\mathrm{CNB}$ and second-round FNA identifies $97 \%$ of nodules with prior inadequate FNA [9-14]. Therefore, chances of tailoring the surgical approach and reducing unnecessary surgery are substantial [25].

In the present study, our aim was to investigate the potential role of CNB as a first-line technique instead of conventional FNA for assessing thyroid nodules at risk of cancer by ultrasonography. To date, this particular approach has not been studied. It is generally accepted that the likelihood of malignancy rises if risk features are identified in a thyroid nodule by US $[1,2]$, and that FNA should be repeated under these circumstances, regardless of a benign cytologic result [6-8]. Recently, the diagnostic utility of CNB was explored in sonographically suspicious thyroid nodules with initially benign cytologies, exposing a $32 \%$ rate of cancer [26]; in agreement with previous reports [9-15], CNB provided reliable diagnostic accuracy, reducing the need for repetitive FNA or diagnostic surgery.

Herein, we selected 72 patients with suspicious thyroid nodules for either CNB or FNA as the first-line diagnostic 


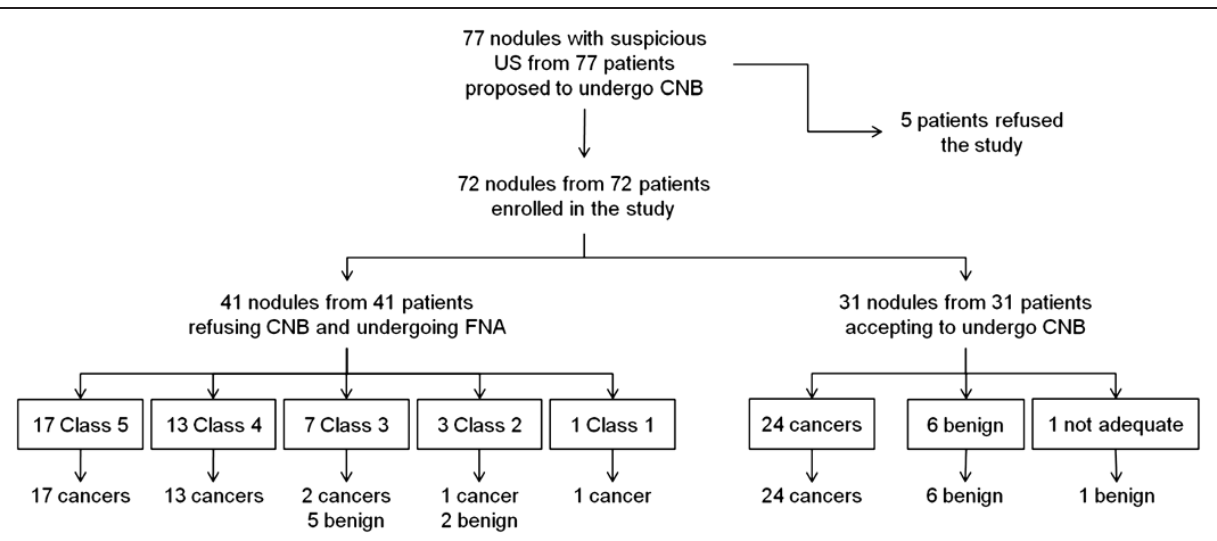

Figure 1 Study design and main results.

procedure, comparing subsequent results. An $80 \%$ malignancy rate was recorded because patients were at risk for cancer. Ultimately, CNB (97\%) significantly outperformed FNA (78\%) in terms of diagnostic accuracy. FNA results also failed to reflect four cancers with a $2.5 \%$ rate of false negatives (class 2), and five other benign lesions were cytologically indeterminate. Furthermore, there were no false negatives by $\mathrm{CNB}$, and only one benign nodule was inadequate at $\mathrm{CNB}$ sampling.

Thyroid cytology is recognized as accurate, but its limitations with respect to misdiagnosis must be acknowledged. Aside from a certain percentage of inconclusive diagnoses by cytology demonstrated here (8/41, 19\%), the potential for false results also exists. False negatives may be due poorly cellular aspirates or sampling error [27], approaching $11 \%$ in large and cystic lesions [28]. Similarly, papillary cancer may be misclassified as benign, owing to macrofollicular presentation in the absence of tell-tale cytologic alterations and architectural

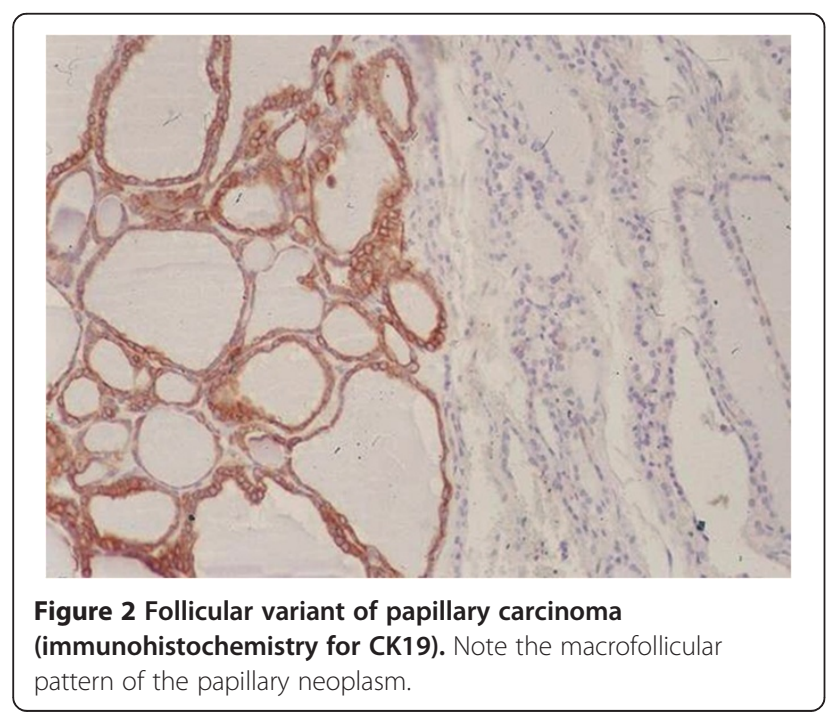

atypia (microfollicular or papillary pattern). In a recent paper, most false negatives were attributable to the follicular variant of papillary cancer [29]. Importantly, it must be emphasized that cancers not easily detected by FNA have higher rates of vascular and capsular invasion, increasing the odds of persistent disease [30]. On the other hand, the cutting needles of CNB enable microhistologic sampling of both large and small size thyroid nodules, with a high degree of accuracy. Expanding on our previous reports [9-14,26], we have shown for the first time that CNB should be considered the first-line approach in nodules defined at-risk by US to avoid falsenegative results and to reduce the reports found to beinconclusive by FNA.

Furthermore, patient tolerability of CNB during this study was excellent, as we previously reported [15]. In

Table 2 Final histologic diagnosis of 34 cancers from fine-needle aspiration (FNA) group

\begin{tabular}{|c|c|c|}
\hline $\begin{array}{l}\text { Cytologic } \\
\text { class }\end{array}$ & Cases (n) & Histology \\
\hline Class 1 & 1 & Follicular variant of papillary carcinoma \\
\hline Class 2 & 1 & Follicular variant of papillary carcinoma \\
\hline \multirow[t]{2}{*}{ Class 3} & 2 & Hürthle cell carcinoma $(n=1)$ \\
\hline & & $\begin{array}{l}\text { Follicular variant of papillary carcinoma } \\
(n=1)\end{array}$ \\
\hline \multirow[t]{3}{*}{ Class 4} & 13 & Classic papillary carcinoma $(n=4)$ \\
\hline & & $\begin{array}{l}\text { Follicular variant of papillary carcinoma } \\
(n=7)\end{array}$ \\
\hline & & Hürthle cell carcinoma $(n=2)$ \\
\hline \multirow[t]{3}{*}{ Class 5} & 17 & Classic papillary carcinoma $(n=13)$ \\
\hline & & $\begin{array}{l}\text { Follicular variant of papillary carcinoma } \\
(n=3)\end{array}$ \\
\hline & & $\begin{array}{l}\text { Columnar variant of papillary carcinoma } \\
(n=1)\end{array}$ \\
\hline
\end{tabular}

Legend: class 1, inadequate;class 2, benign;class 3, indeterminate;class 4 , suspicious for malignancy;class 5 , malignant. 
addition, responses to a questionnaire evaluating patient comfort level confirmed previous findings (data not shown).

For clinical practice, based on our previous experience and according to the present data, we were discouragedfrom repeating FNA after an initial inconclusive cytologic report. In this circumstance, as well as in the occurrence of recently discovered thyroid nodules defined as 'suspicious for malignancy', CNB should be used. This approach could avoid the 'risk' of false negative FNA and a delay in diagnosing thyroid cancers.

\section{Conclusions}

In conclusion, our findings indicate a higher rate of diagnostic accuracy with first-line use of CNB than FNA for assessing at-risk thyroid nodules identified by US. The false negatives and inconclusive results of FNA may also be reduced making $\mathrm{CNB}$ the preferred method in this setting.

\section{Abbreviations \\ CFD: color flow Doppler; CNB: core needle biopsy; FNA: fine-needle aspiration; RTE: real-time elastography; US: ultrasonography.}

\section{Competing interests}

The authors declare that they have no competing interests.

\section{Authors' contributions}

PT, GN, NN, SA, ST, DDCM: acquisition of data, drafting of manuscript; PT, GN, SV, MC: study conception and design; PT, NN: performed ultrasound examination; NN: performed FNA and CNB; AC, ST, LeGu: analysis and interpretation of FNA and CNB data; AL, FR, LuGi: critical revision and supervision. All authors read and approved the final manuscript.

\section{Author details}

${ }^{1}$ Section of Endocrinology and Diabetology, Ospedale Israelitico, Rome, Italy. ${ }^{2}$ Section of Surgery, Ospedale Israelitico, Rome, Italy. ${ }^{3}$ Section of Pathology, Ospedale Israelitico, Rome, Italy. ${ }^{4}$ Department of Experimental Medicine, Sapienza University, Rome, Italy. ${ }^{5}$ Department of Surgical and Medical Sciences, Sapienza University, Ospedale S. Andrea, Rome, Italy. ${ }^{6}$ Department of Medico-Surgical Sciences and Biotechnologies, Sapienza University, Latina, Italy. ${ }^{7}$ Department of Nuclear Medicine and Thyroid Center, Oncology Institute of Southern Switzerland, Bellinzona, Switzerland.

Received: 4 November 2013 Accepted: 16 March 2014 Published: 24 March 2014

\section{References}

1. Gharib H, Papini E, Paschke R, Duick DS, Valcavi R, Hegedüs L, Vitti P, AACE/ AME/ETA Task Force on Thyroid Nodules: American Association of Clinical Endocrinologists, Associazione Medici Endocrinologi, and European Thyroid Association medical guidelines for clinical practice for the diagnosis and management of thyroid nodules. J Endocrinol Invest 2010, 33:1-50.

2. American Thyroid Association (ATA) Guidelines Taskforce on Thyroid Nodules and Differentiated Thyroid Cancer, Cooper DS, Doherty GM, Haugen BR, Kloos RT, Lee SL, Mandel SJ, Mazzaferri EL, Mclver B, Pacini F, Schlumberger M, Sherman SI, Steward DL, Tuttle RM: Revised American Thyroid Association management guidelines for patients with thyroid nodules and differentiated thyroid cancer. Thyroid 2009, 19:1167-1214.

3. Solbiati L, Osti V, Cova L, Tonolini M: Ultrasound of thyroid, parathyroid glands and neck lymph nodes. Eur Radiol 2001, 11:2411-2424.

4. Kim EK, Park CS, Chung WY, Oh KK, Kim DI, Lee JT, Yoo HS: New sonographic criteria for recommending fine-needle aspiration biopsy of nonpalpable solid nodules of the thyroid. Am J Roentgenol 2002, 178:687-691.

5. Trimboli P, Guglielmi R, Monti S, Misischi I, Graziano F, Nasrollah N, Amendola S, Morgante SN, Deiana MG, Valabrega S, Toscano V, Papini E: Ultrasound sensitivity for thyroid malignancy is increased by real-time elastography: a prospective multicenter study. I Clin Endocrinol Metab 2012, 97:4524-4530.

6. Kwak JY, Kim EK, Kim HJ, Kim MJ, Son EJ, Moon HJ: How to combine ultrasound and cytological information in decision making about thyroid nodules. Eur Radiol 1923-1931, 2009:19.

7. Maia FF, Matos PS, Pavin EJ, Vassallo J, Zantut-Wittmann DE: Value of repeat ultrasound-guided fine-needle aspiration in thyroid nodule with a first benign cytologic result: impact of ultrasound to predict malignancy. Endocrine 2011, 40:290-296.

8. Choi YJ, Jung I, Min SJ, Kim HJ, Kim JH, Kim S, Park JS, Shin JH, Sohn YM, Yoon JH, Kwak JY: Thyroid nodule with benign cytology: is clinical follow-up enough? PLOS ONE 2013, 8(5):e63834.

9. Screaton NJ, Berman LH, Grant JW: US-guided core-needle biopsy of the thyroid gland. Radiol 2003, 226:827-832.

10. Park KT, Ahn SH, Mo JH, Park YJ, Park J d, Choi SI, Park SY: Role of core needle biopsy and ultrasonographic finding in management of indeterminate thyroid nodules. Head Neck 2011, 33:160-165.

11. Sung JY, Na DG, Kim KS, Yoo H, Lee H, Kim JH, Baek JH: Diagnostic accuracy of fine-needle aspiration versus core-needle biopsy for the diagnosis of thyroid malignancy in a clinical cohort. Eur Radiol 2012, 22:1564-1572

12. Na DG, Kim JH, Sung JY, Baek JH, Jung KC, Lee H, Yoo H: Core-needle biopsy is more useful than repeat fine-needle aspiration in thyroid nodules read as nondiagnostic or atypia of undetermined significance by the Bethesda system for reporting thyroid cytopathology. Thyroid 2012, 22:468-475.

13. Samir AE, Vij A, Seale MK, Halpern E, Faquin WC, Parangi S, Hahn PF, Daniels $\mathrm{GH}$ : Ultrasound-guided percutaneous thyroid nodule core biopsy: clinical utility in patients with prior nondiagnostic fine-needle aspirate. Thyroid 2012, 22:461-467.

14. Nasrollah N, Trimboli P, Guidobaldi L, CicciarellaModica DD, Ventura C, Ramacciato G, Taccogna S, Romanelli F, Valabrega S, Crescenzi A: Thin core biopsy should help to discriminate thyroid nodules cytologically classified as indeterminate. A new sampling technique. Endocrine 2013, 43:659-665.

15. Nasrollah N, Trimboli P, Rossi F, Amendola S, Guidobaldi L, Ventura C, Maglio R, Nigri G, Romanelli F, Valabrega S, Crescenzi A: Patient's comfort with and tolerability of thyroid core needle biopsy. Endocrine 2013, 45:79-83.

16. Frates MC, Benson CB, Charboneau JW, Cibas ES, Clark OH, Coleman BG, Cronan JJ, Doubilet PM, Evans DB, Goellner JR, Hay ID, Hertzberg BS, Intenzo CM, Jeffrey RB, Langer JE, Larsen PR, Mandel SJ, Middleton WD, Reading CC, Sherman SI, Tessler FN, Society of Radiologists in Ultrasound: Management of thyroid nodules detected at US: Society of Radiologists in Ultrasound consensus conference statement. Radiol 2005, 237:794-800.

17. Rago T, Vitti P, Chiovato L, Mazzeo S, De Liperi A, Miccoli P, Viacava P, Bogazzi F, Martino E, Pinchera A: Role of conventional ultrasonography and color flow-Doppler sonography in predicting malignancy in 'cold' thyroid nodules. Eur J Endocrinol 1998, 138:41-46.

18. De Lellis R, Lloyd R, Heitz P, Eng C: Pathology and genetics of tumour of endocrine organs. In World Health Organization Classification of Tumours. Edited by Kleihues P, Sobin L. Lyon, France: IARC; 2004:49-133.

19. Bartolazzi A, Orlandi F, Saggiorato E, Volante M, Arecco F, Rossetto R, Palestini N, Ghigo E, Papotti M, Bussolati G, Martegani MP, Pantellini F, Carpi A, Giovagnoli MR, Monti S, Toscano V, Sciacchitano S, Pennelli GM, Mian C, Pelizzo MR, Rugge M, Troncone G, Palombini L, Chiappetta G, Botti G, Vecchione A, Bellocco R, Italian Thyroid Cancer Study Group (ITCSG): Galectin-3-expression analysis in the surgical selection of follicular thyroid nodules with indeterminate fine-needle aspiration cytology: a prospective multicentre study. Lancet Oncol 2008, 9:543-549.

20. Saggiorato E, De Pompa R, Volante M, Cappia S, Arecco F, Dei Tos AP, Orlandi F, Papotti M: Characterization of thyroid 'follicular neoplasms' in fine-needle aspiration cytological specimens using a panel of immunohistochemical markers: a proposal for clinical application. Endocr Relat Cancer 2005, 12:305-317.

21. Treglia G, Caldarella C, Saggiorato E, Ceriani L, Orlandi F, Salvatori M, Giovanella L: Diagnostic performance of $99 \mathrm{mTc}-\mathrm{MIBI}$ scan in predicting 
the malignancy of thyroid nodules: a meta-analysis. Endocrine 2013, 44:70-78.

22. Trimboli P, Condorelli E, Catania A, Sorrenti S: Clinical and ultrasound parameters in the approach to thyroid nodules cytologically classified as indeterminate neoplasm. Diagn Cytopathol 2009, 37:783-785.

23. Mathur A, Weng J, Moses W, Steinberg SM, Rahbari R, Kitano M, Khanafshar E, Ljung BM, Duh QY, Clark OH, Kebebew E: A prospective study evaluating the accuracy of using combined clinical factors and candidate diagnostic markers to refine the accuracy of thyroid fine needle aspiration biopsy. Surgery 2010, 148:1170-1177.

24. Cibas ES, Ali SZ: The Bethesda system for reporting thyroid cytopathology. Thyroid 2009, 19:1159-1165.

25. Sebo TJ: What are the keys to successful thyroid FNA interpretation? Clin Endocrinol 2012, 77:13-17.

26. Ha EJ, Baek JH, Lee JH, Song DE, Kim JK, Shong YK, Hong S. Sonographically suspicious thyroid nodules with initially benign cytologic results: the role of a core needle biopsy. Thyroid 2013, 23:703-708

27. Kini SR: Thyroid Cytopathology: an Atlas and Text. Philadelphia, USA: Lipincott Williams \& Wilkins; 2008.

28. Meko JB, Norton JA: Large cystic/solid thyroid nodules: a potential falsenegative fine-needle aspiration. Surgery 1995, 118:996-1004.

29. Mehanna R, Murphy M, McCarthy J, O'Leary G, Tuthill A, Murphy MS, Sheahan P: False negatives in thyroid cytology: impact of large nodule size and follicular variant of papillary carcinoma. Laryngoscope 2013, 123:1305-1309.

30. Yeh MW, Demircan O, Ituarte P, Clark OH: False-negative fine-needle aspiration cytology results delay treatment and adversely affect outcome in patients with thyroid carcinoma. Thyroid 2004, 14:207-215.

doi:10.1186/1477-7819-12-61

Cite this article as: Trimboli et al.: The use of core needle biopsy as first-line in diagnosis of thyroid nodules reduces false negative and inconclusive data reported by fine-needle aspiration. World Journal of Surgical Oncology 2014 12:61

\section{Submit your next manuscript to BioMed Central and take full advantage of:}

- Convenient online submission

- Thorough peer review

- No space constraints or color figure charges

- Immediate publication on acceptance

- Inclusion in PubMed, CAS, Scopus and Google Scholar

- Research which is freely available for redistribution 